\title{
DESAFIOS CONTEMPORÂNEOS PARA A ANTROPOLOGIA NO BRASIL SINAIS DE UMA NOVA TRADIÇÃO ETNOGRÁFICA E DE UMA RELAÇÃO DISTINTA COM OS SEUS "OUTROS"
}

\author{
JOÃO PACHECO DE OLIVEIRA ${ }^{1}$
}

\begin{abstract}
RESUMO
Nas antropologias hegemônicas o desafio para o pensamento crítico é romper com 0 exotismo e ter capacidade de compreender as práticas e a vida cotidiana. Para os antropólogos brasileiros se impõe além disso uma atenção especial à dimensão reflexiva e as condições sociais de produção de conhecimento. 0 pesquisador não pode jamais imaginar-se como um sujeito radicalmente exterior às disputas e classificações sociais, supondo haver feito tabula rasa das múltiplas representações e interesses que estão em torno de sua etnografia. A produção científica precisa ser analisada não por meio de auto-representações engendradas a partir da importação descontextualizada de conhecimentos, mas sim através de uma análise minuciosa das práticas concretas de investigação postas em prática, dos resultados obtidos e buscando tomar consciência do campo de possibilidades em que se movimenta e de seus limites. Pensar as tradições etnográficas de maneira plural, como resultado de uma autoconsciência progressiva quanto à eficácia, limites e singularidade dessas práticas específicas de investigação, pode representar uma forma positiva e criativa de frepensar a história e as perspectivas dessa disciplina.
\end{abstract}

\section{PaLAVRas ChaVe \\ Antropologia do Conhecimento; Tradições Etnográficas; Antropologias Periféricas; Reflexividade}

\author{
CONTEMPORARY CHALLENGES FOR AN ANTHROPOLOGY IN BRAZIL: SIGNS OFA NEW \\ ETHNOGRAPHIC TRADITION AND OF A DIFFERENT RELATIONSHIP WITH THEIR "OTHERS"
}

\begin{abstract}
In hegemonic anthropologies, the challenge for critical thinking is to break with exoticism and understand the practices of everyday life. For Brazilian anthropologists, special attention is also given to the reflexive dimension and social conditions of knowledge production. The researcher can never imagine himself as a subject radically foreign to social disputes and classifications and make a clean sweep of the multiple representations and interests that surround his ethnography. The scientific production needs to be analyzed not by means of the self-representations generated from the decontextualized import of knowledge, but through a careful analysis of the concrete research practices, the results produced and trying to be aware of the field of possibilities and its limits. Thinking about ethnographic traditions in a plural way, as a result of a progressive self-consciousness regarding the effectiveness, limits and singularity of specific research practices, can represent a positive and creative way to rethink the history and perspectives of the discipline.
\end{abstract}

\section{KEY WORDS}

Anthropology of Knowledge; Ethnographic Traditions; Peripheral Anthropologies; Reflexivity

\footnotetext{
${ }^{1}$ Museu Nacional - UFRJ
} 


\title{
DÉFIS CONTEMPORAINS POUR L'ANTHROPOLOGIE AU BRÉSIL: SIGNES D'UNE NOUVELLE TRADITION ETHNOGRAPHIQUE ET D'UNE RELATION DIFFÉRENTE AVEC LEURS "AUTRES"
}

\begin{abstract}
RÉSUME
Dans les anthropologies hégémoniques, le défi pour la pensée critique est de rompre avec l'exotisme et de mieux comprendre les pratiques et la vie quotidienne. Pour les anthropologues brésiliens, une attention particulière est accordée à la dimension réflexive et aux conditions sociales de la production du savoir. Le chercheur ne peut jamais s'imaginer en tant que sujet radicalement en dehors des conflits et des classifications sociales, à supposer qu'il soit invisible pour les multiples représentations et intérêts qui entourent son ethnographie. La production scientifique doit être analysée non par des autoreprésentations engendrées par l'importation décontextualisée des connaissances, mais par une analyse approfondie des pratiques de recherche concrètes mises en pratique, des résultats obtenus et en prenant conscience du champ des possibles dans lequel il s'inscrit. Penser les traditions ethnographiques d'une manière plurielle, en raison de la conscience de soi progressive quant à l'efficacité, aux limites et à l'unicité de ces pratiques de recherche particulières, peut représenter une manière positive et créative d’aborder l'histoire et les perspectives de cette discipline.
\end{abstract}

\section{MOTS CLÉS}

\section{Anthropologie de la connaissance; Traditions ethnographiques; Anthropologies} périphériques Réflexivité

\section{DESAFÍOS CONTEMPORÁNEOS PARA LA ANTROPOLOGÍA NO BRASIL: SIGNOS DE UNA NUEVA TRADICIÓN ETNOGRÁFICA Y DE UNA RELACIÓN DISTINTA CON SUS "OTROS"}

\begin{abstract}
RESUMEN
En las antropologías hegemónicas el desafío para el pensamiento crítico es romper con el exotismo y comprender lo cotidiano. Para los antropólogos brasilenõs se impone además una atención especial a la dimensión reflexiva y a las condiciones sociales de la producción de conocimientos. El investigador no puede jamás imaginarse como un sujeto radicalmente extraño a las disputas y clasificaciones sociales y hacer tabla rasa de las múltiples representaciones e intereses que rodean su etnografía. La produción científica precisa ser analizada no por medio de las auto-representaciones engendradas a partir de la importación descontextualizada de conocimientos, sino a través de un análisis cuidadoso de las prácticas concretas de investigación, de los resultados producidos y procurando tomar conciencia del campo de posibilidades y de sus límites. Pensar las tradiciones etnográficas de manera plural, como resultado de una autoconciencia progresiva en cuanto a la eficacia, limites y singularidad de prácticas específicas de investigación, puede representar una forma positiva y creativa para repensar la historia y las perspectivas de la disciplina.
\end{abstract}

\section{PALAVRAS-CLAVE}

Antropología del Conocimiento; Tradiciones Etnográficas; Antropologías Periféricas; Reflexividad 


\section{O MITO DE ORIGEM DAS ANTROPOLOGIAS PERIFÉRICAS}

A história de uma "antropologia periférica"² nunca começa no próprio país, mas sim nos espaços metropolitanos, onde foram instituídas as galerias de "pais-fundadores" e se constituíram as genealogias científicas. Nessa linha os cursos de graduação em ciências sociais, descritos como momentos iniciais de profissionalização, foram seguidos mais tarde pela implantação de programas de pós-graduação, demarcando o conhecimento como um produto exclusivamente universitário. Tudo aquilo que os precede é pensado apenas como "pré-história", a qual poderia ter apenas a limitada utilidade de uma certa erudição, mas não contribuiria com conhecimentos científicos nem com instrumentos analíticos que pudessem colaborar de maneira efetiva para a investigação e o trabalho antropológico. Numa perspectiva provinciana e colonizada os historiadores da disciplinas buscam sempre o ponto zero da antropologia nesses países. Ou seja, procuram separar em definitivo e de maneira pretensamente inequívoca, de um lado, as formas legítimas de produção de conhecimento e os parâmetros profissionais pensados como os únicos corretos, uma pura reprodução de antropologias metropolitanas, e de outro lado, as práticas não científicas, não legítimas e puramente de amateurs, que identificam com os autores e tradições nacionais.

Também desta maneira o historia da antropologia é pensada somente como um processo de importação de conhecimentos universitários específicos. A iniciação à disciplina é feita primordialmente através da leitura de manuais e de histórias da antropologia (com suas "escolas" e "correntes"). Embora tragam informações importantes é fundamental entender que se trata de obras dirigidas originalmente a um público universitário metropolitano, que a sua tradução pura e simples, sem adaptações e mediações (indispensáveis para um público estrangeiro) não implica em uma compreensão profunda dos seus objetivos e métodos, nem pode automaticamente instituir atitudes ou práticas científicas. Em seguida os estudantes de antropologia passam ao estudo de monografias exemplares e exposições de método, entre as quais estão rigorosamente ausentes as menções às produções nacionais. Dos povos mencionados só aprendem os nomes, que muitas vezes nem sabem localizar em mapas e desconhecem totalmente a sua densidade histórica e a sua existência contemporânea. Como depois dessa prática de ensino e formação os jovens antropólogos podem pensar em protagonismo indígena e descolonização do conhecimento senão como um exercício retórico, que apenas repete as eventuais rupturas e novas problemáticas de uma antropologia supostamente universal?

\footnotetext{
${ }^{2}$ Expressão utilizada por Roberto Cardoso de Oliveira (1999) para designar antropologias (como as latino-americanas) que emergem fora da Europa Ocidental e dos Estados Unidos, ou seja, de contextos hegemônicos em termos econômicos e políticos, nos quais se desenvolvem as "antropologias centrais".
} 
Nos cursos temáticos a bibliografia teórica também é exclusivamente externa, enquanto os autores nacionais figuram apenas como contribuições recentes à investigação. No máximo, servem para dar uma cor local às escolas e às correntes (supostamente universais), em função de exercícios concretos de aplicação. Teorias, métodos de investigação e legitimidade científica são vistos unicamente como se fossem bens de importação. De uma condição periférica surge então uma antropologia subalterna, inserida em uma divisão internacional do trabalho e dentro de uma hierarquia bem definida que the é profundamente adversa.

É necessário um esforço crítico quanto às modalidades concretas de existência destas antropologias periféricas. Ao qualificá-las assim, o meu objetivo é chamar a atenção para uma relação de dependência com outras modalidades (imperiais ou nacionais) de antropologia, supostamente mais legítimas e universais. Mesmo a chamada crítica póscolonial, ainda centrada no mundo anglófono, fala de uma perspectiva bastante específica.

As formas concretas e o grau de intensidade da incorporação dos reinos e estados da Índia e do Oriente não foram os mesmos que aqueles registrados com as populações autóctones na América. A paradoxal coexistência entre, por um lado, a presença de tradições pré-coloniais em estruturas cotidianas (religiosas, linguísticas e sociais) e, por outro, o uso da língua inglesa como canal principal de comunicação implicam condições bastante diferentes daquelas observadas nas Américas para o desenvolvimento de antropologias.

O domínio colonial dos espanhóis e dos portugueses nesta parte do planeta foi muito distinto, com a desestruturação de impérios preexistentes e uma reconfiguração muito mais profunda do modo de vida das populações originárias. Tampouco thes deixou como legado linguístico sua inserção em uma comunidade hegemônica (de língua inglesa), tornando distintas suas estratégias e seus projetos de futuro.

Caracterizar tais antropologias (que por definição são "segundas") como periféricas, destacando com isso sua dependência em face das antropologias hegemônicas, é sem dúvida um passo importante. Entretanto, no meu modo de ver, para entendê-las em seu dinamismo, é necessário um esforço etnográfico, teórico e epistemológico para evidenciar as condições sociais em que elas se desenvolvem, quer dizer, os contextos nos quais adquirem funções e significados específicos. Рara que a relação colonial seja uma ferramenta de análise sociológica, é imprescindível que sejamos capazes de entendê-la em sua variabilidade e nas contradições que thes são constitutivas.

No meu entender, cabe aqui a mesma crítica que fazemos ao conceito genérico de "situação colonial", ferramenta fundamental para permitir a importação de uma concepção não europeizante da alteridade: 
"Se em lugar de tratar o "nativo" e o "colonizador" como categorias que são totalizantes, autoevidentes e opostas diametralmente explorássemos sua variabilidade interna, os contextos historicamente diferentes pelos quais se conectam e a multiplicidade de conexões que estão estabelecidas entre estas categorias, poderíamos abrir um novo campo de investigação. Possivelmente então a noção de uma voz indígena singular ("ou modelo nativo") poderia ser substituída por um esforço para evidenciar as diferentes estratégias sociais que fazem esta voz tão diversa e contraditória" (PACHECO DE OLIVEIRA, 2009, p. 101).

Avançar na investigação requer mudar a unidade redutora de uma situação colonial mediante a identificação das múltiplas situações históricas que realmente podem ajudar na compreensão das diferentes formas de organização social e da multiplicidade de estratégias dos colonizados.

As antropologias periféricas também são produtos históricos e sociais, que cruzam por variadas redes de circulação internacional de ideias e que assumem os mais distintos usos e aplicações locais. Falar de antropologias nacionais sem dúvida corresponde a avançar no reconhecimento prévio da diversidade, mas também pode sugerir uma unidade das práticas de produção de conhecimentos que em realidade se atribui desde o exterior, fazendo caso omisso da diversidade de significados e das aplicações que a antropologia tem dentro de cada contexto nacional.

Para evitar isto, trabalhamos aqui com a noção de tradição etnográfica (PACHECO DE OLIVEIRA, 2006, 2013), inspirada pela análise das "tradições de conhecimento" de Barth (1993), dirigindo nossa atenção para o campo da prática (PELS; SALEMINK, 1999) e da interrelação entre os atores sociais (BOURDIEU, 1997), entendendo que tais processos podem e devem ser objeto de estudos empíricos e descrições etnográficas (STOCKING JR., 1968, 1974, 1984, 1988, 1996, 2006).

É necessário ir mais além do discurso normativo e homogeneizador das autorrepresentações acadêmicas (procedam estas das antropologias centrais ou periféricas). As importações de conceitos e métodos das antropologias metropolitanas não podem ser tomadas como se engendrassem espontaneamente sua demanda e regulassem as formas de seu próprio consumo, impondo uma racionalidade e um dinamismo que seriam induzidos do exterior por um sujeito supostamente universal.

É fundamental considerar a antropologia enquanto prática, tratando de perceber como ocorre o enraizamento social desta disciplina e dos conhecimentos que possibilita. Isto deve ser observado principalmente por meio de dois fatores cruciais. Primeiro, a associação que tal antropologia mantém com outros saberes que frequentemente precedem a institucionalização da disciplina, com os quais ela se apresentará como ligada ao contexto nacional. É o caso dos saberes administrativos, morais e cartográficos, bem como suas identificações e limites com outras disciplinas dos estudos das humanidades (história, arqueologia, geografia, sociologia, linguística). 
O segundo serão os usos locais que serão atribuídos à antropologia e aos antropólogos egressos da formação universitária, que podem ser - e frequentemente são muito distintos das formas de profissionalização possível nas antropologias centrais.

Claramente, a institucionalização da antropologia na Inglaterra, nos Estados Unidos e na França possui características muito distintas, bem exploradas já em outros estudos 3 . Desde o início os antropólogos daqueles países se reivindicaram como portadores de um saber científico (e não administrativo, prático ou político), lutando por um espaço próprio entre as disciplinas universitárias. Procuravam assim se inserir em um sistema de produção de conhecimentos já estabelecido e bastante reconhecido. A construção de sua identidade passava pela pretensão de possuírem o monopólio de um saber legítimo sobre o "outro" (ou seja o mundo não europeu), desqualificando assim outros saberes não considerados científicos. È o caso de viajantes, missionários, administradores). Também está na origem dos conflitos sobre fronteiras com outras disciplinas universitárias (sociologia, história, geografia, arqueologia, linguística), preformatando formas de falar sobre o seu objeto.

O uso pelos governos e pela opinião pública dos dados antropológicos eгa justificado por sua qualidade e confiabilidade, por serem mais exatos, profusos e apresentados de forma neutra. Isso os tornava mais susceptíveis de serem utilizados como subsídios para políticas públicas e para a tomada de decisões por agentes governamentais. As etnografias produzidas pelos antropólogos sobre o mundo não europeu serviram de apoio para políticas coloniais (especialmente na legitimação do "governo indireto" - "Indirect Rule").

Mas os contextos sociais não foram transplantados junto com as normativas disciplinares nem com as expectativas que estas suscitavam quanto ao conhecimento científico! Ao contrário, foram os contextos sociais próprios às jovens nações, os que se apropriaram daquele conjunto de conhecimentos supostamente universais e científicos, ressignificando-os e propiciando o surgimento de intelectuais que se identificariam como "antropólogos".

\section{PLURALIZANDO TRADIÇÕES ETNOGRÁFICAS}

Que populações se constituiriam em objeto de investigação e reflexão para os primeiros intelectuais que, no Brasil, se definiram como "antropólogos"? Foram as populações claramente portadoras de instituições diferentes das ocidentais; basicamente, as mesmas sobre as quais a antropologia colonial realizou suas experiências iniciais e em função das quais reivindicava, por contraposição ao saber administrativo e às intervenções religiosas,

\footnotetext{
${ }^{3}$ Veja-se Stocking Jr (1968, 1974, 1984), Kuper (1973, 1999), Copans; Jamin (1977), L' Étoile (2004), entre outros.
} 
um conhecimento imaginado como superior e de natureza científica (EVANS-PRITCHARD; FORTES, 1970 [1940]).

Os primeiros antropólogos brasileiros seguiram os rastros dos investigadores norteamericanos e franceses que estiveram no país entre as décadas de 1930 e 1950, dirigindo seu foco principal de interesse seja para as sociedades e culturas indígenas, seja para as tradições religiosas chamadas afro-brasileiras. Só que, neste caso, os "outros" não estavam distantes a milhares de quilômetros nem eram o objeto precípuo de uma ação de governos coloniais, estruturada no fundo por princípios militares (onde o "outro" era virtualmente sinônimo de "inimigo" ou de população subjugada). A construção de uma "alteridade interna" ${ }^{4}$ não foi apenas um detalhe ou um acidente histórico, mas sim teve implicações profundas entre nós para o exercício de uma ciência hermenêutica como a antropologia.

Nos países hegemônicos - onde tais formas de humanidade foram pensadas e sentidas como absolutamente exteriores e incompreensíveis, bem como naqueles em que a ação colonial parecia distante do cotidiano da maioria dos cidadãos - o desafio para o pensamento crítico foi romper com o exotismo como eixo propulsor da investigação antropológica (BENSA, 2006). É indispensável dissolver a invisibilidade da ação colonial, que deve passar a ser vista como parte indissociável da vida metropolitana, como nos recordava Jean Bazin (2002, p. 50): "Por mais afastado ou com acesso difícil que seja, o campo não é para nós jamais algo verdadeiramente alheio, uma vez que já estamos ali se localizados" (minha tradução).

Nas antropologias periféricas, o desafio deveria ser o contrário - não se trata tanto de recuperar o distante embora próximo e o exótico como cotidiano, mas sim dirigir a atenção para coisas comuns e compartilhadas, carregadas com diferentes interpretações, objeto de paixões e interesses variados. O investigador não pode fazer tábula rasa das múltiplas representações e teorias sobre o que conduz sua etnografia, nem tão pouco imaginar-se a si mesmo como um sujeito radicalmente estranho às disputas sociais. As suas condições peculiares de produção impõe uma atenção especial à dimensão reflexiva, sem a qual é impossível compreender o tipo de conhecimento que produz.

Tal conhecimento, assim como as teorias e as ferramentas da investigação, não resulta em uma simples cópia, reproduzida mecanicamente ou clonada das antropologias hegemônicas, já que está necessariamente está carregado de outras potencialidades que precisam ser identificadas pela etnografia da ciência e examinadas criticamente à luz de parâmetros teóricos, epistemológicos e políticos, que devem ser explicitamente formulados e assumidos.

\footnotetext{
${ }^{4}$ Veja-se Esteban Krotz (2002).
} 
Um aspecto perverso e limitador da antropologia hegemônica e de suas cópias pelos colonizados é o abuso na utilização de termos como "nativos" e "selvagens", assim como a insistência em caracterizá-los meramente como "informantes". O pressuposto aqui contido é de que a sua humanidade (enquanto "selvagens") está sempre expressa em modalidades autônomas e distintas de pensamento. Com isto se procede a um completo esquecimento das relações de força e sujeição, celebra-se o exotismo e implicitamente transforma-se modos de dominação e conflitos de classe, gênero e etnia puramente em "diferenças culturais".

Estas são práticas ainda bastante correntes na investigação e no ensino da antropologia no contexto da América Latina, sobretudo em programas de pós-graduação 5 , que tiveram que coexistir durante longos períodos com ditaduras militares, importando modelos de universidades prestigiosas do primeiro mundo. A implementação da antropologia como disciplina universitária em sociedades rigidamente estratificadas e muito exclusivas, teve como um corolário inevitável só permitir o acesso a jovens procedentes de elites econômicas e intelectuais.

Tudo favorecia assim apropriar-se de protocolos de investigação da tradição etnográfica da primeira metade do século XX, apelidando-os de "antropologia clássica", para legitimar o desapego e distanciamento que mantinham face aos principais problemas, autores e debates nacionais anteriores. Que frequentemente eram provenientes de outras disciplinas e formações intelectuais, mas que foram muito importantes na produção de conhecimentos em relação ao seu próprio país.

Para a maioria dos intelectuais brasileiros, índios e sobretudo negros nunca foram objetos exóticos ou desconhecidos, mas sim pessoas que pertenciam a grupos sociais claramente delimitados, que integravam o seu horizonte político e econômico e muitas vezes partilhavam do seu cotidiano. Era a partir dessas classificações e experiências que os intelectuais refletiam sobre eles - em geral como objetos, muito raramente como sujeitos usando as teorias científicas consagradas na sua época (que frequentemente eram contraditórias entre si e lhe deixavam ampla margem de escolhas possíveis). Em suas obras artísticas exploraram também intensamente, uma dimensão emocional e afetiva de suas relações com tais populações. Em diversos contextos públicos se manifestaram a respeito das classificações jurídicas e sociais de que índios e negros foram objeto. Finalmente dialogaram de maneira ativa e respaldaram linhas de atuação administrativa em relação a estas "alteridades internas". Por mais que pensassem reproduzir as estratégias de investigação, os tropos narrativos e as argumentações usuais nas antropologias

\footnotetext{
${ }^{5}$ Ver Miceli (1993) para uma investigação muito atenta e rigorosa sobre o surgimento das pósgraduações no Brasil e a influência dos organismos de financiamento (públicos e privados, nacionais ou não) em tal processo.
} 
hegemônicas, a busca de autonomização das antropologias periféricas teve que lutar com uma configuração de relações sociais muito distintas entre sujeito e objeto de conhecimento.

Рага a compreensão e análise da formação de uma comunidade antropológica seria bastante empobrecedor, acredito, ceder a uma visão redutora e falsamente universalizante, ignorando por completo as suas especificidades e repetindo a metáfora aplicada, no plano econômico, a países "em desenvolvimento". Como também, inversamente, não considerar os processos sociais concretos e as disputas econômicas e clivagens políticas de que resultaram estas formas de conhecimento, glorificando ingenuamente tais antropologias como expressão pura (ou seja, romantizada e jamais investigada) de outras epistemologias.

Um exemplo a seguir evidencia a complexidade destas antropologias e dos desafios que devem enfrentar. A obra do Gilberto Freyre, por exemplo, aponta alguns riscos desta segunda tendência. Ele foi o primeiro intelectual a ostentar no Brasil de maneira explícita o título de antropólogo. Seus escritos contribuíram para deslocar a visão objetificada do "outro" (o "outro interno", que no caso de seus escritos corresponderia ao negro), apresentando uma visão bastante complexa das formas de dominação. O "nós" com que Gilberto Freyre pensa o Brasil não é mais o puro colonizador europeu, ele coloca no centro de seus estudos, ao contrário, o mestiço brasileiro e seus específicos costumes (que representam uma mescla de instituições portuguesas, africanas e indígenas). Mais adiante ele chega a falar em uma nova ciência, a tropicologia, que teria como foco o estudo do homem nos trópicos, identificando uma forma de humanidade com um contexto climático e identidades regionais. Em seus últimos trabalhos, no entanto, aquilo que ao início de sua obra havia sido uma contribuição muito original, terminou por transformar-se, paradoxalmente, em uma apologia da lusofonia.

\section{INDÍGENAS E PRODUÇÃO DE CONHECIMENTO NO BRASIL}

Reparemos nas práticas e nas representações sobre os indígenas, as quais precedem amplamente a implantação da antropologia nestes contextos nacionais. Tais ideias, atitudes e expectativas continuam integrando referentes ideológicos compartilhados em grande parte pelos cientistas sociais, já que estão solidamente estabelecidas em sua condição de classe e no cenário de sua vida cotidiana. Para um exercício verdadeiramente crítico da antropologia, estas práticas e representações - que preexistem as suas experiências como pesquisadores e cientistas - precisam ser melhor conhecidas, assim como também precisam ser melhor descritos e analisados os seus possíveis impactos no próprio processo de conhecimento.

O primeiro aspecto a considerar é a influência do indianismo na formação da classe dirigente e dos intelectuais brasileiros. A extensa produção de artistas (poetas, novelistas, 
pintores, escultores, músicos) e pensadores na segunda metade do século XIX penetrou em todas as camadas sociais, conformando as bases do que o brasileiro médio pensa e sente sobre os indígenas. Isso poderia ser resumido de maneira singela na seguinte postura: "Basicamente, todos os brasileiros descendem dos indígenas, que eram pessoas nobres e altivas antes da chegada dos colonizadores. O tratamento algumas vezes duro recebido por parte dos portugueses, associado às epidemias e a sua dificuldade em adaptar-se ao modo de vida da colônia, levou ao seu extermínio quase completo. Daquele passado glorioso apenas sobreviveram uns poucos grupos em situações remotas, enquanto se encontram vestígios dispersos e frequentes na toponímia, nas lembranças familiares e nos costumes".

O processo histórico da independência - realizado sem uma ruptura na forma política (monarquia), que se manteve vinculada à mesma dinastia portuguesa - parece ter ficado inconcluso. Paradoxalmente, coube à arte e ao pensamento social brasileiro promover aquilo que a política não tinha realizado, apartando no plano afetivo e simbólico a jovem nação de sua antiga potência colonizadora. Por meio da revalorização de um indígena como antepassado e de uma herança indígena - bastante dispersa mas bastante revalorizada (incluindo descendência, modos de afetividade e relações com a natureza tropical) - os brasileiros se distanciaram de uma origem portuguesa e construíram para si mesmos, ainda durante o Império, uma identidade nacional bem específica (PACHECO DE OLIVEIRA, 2009).

O segundo aspecto a levar em conta é a existência de uma agência estatal específica (Serviço de Proteção ao Índio - SPI) criada em 1910, sob o controle de militares positivistas, a qual conduziu à consolidação de um verdadeiro saber administrativo, o chamado "sertanismo"6 ou "rondonismo"7. Mais que a observação dos costumes indígenas ou a incorporação de conhecimentos antropológicos em seus procedimentos práticos, valorizaram principalmente as experiências diretas de contato e "pacificação" dos indígenas realizadas por agentes governamentais. A visão romântica (herdada do indianismo) continuou inspirando as intervenções práticas, associada desde o começo a uma perspectiva autoritária e paternalista na qual se reafirmavam a incapacidade civil do indígena e a necessidade absoluta de uma tutela protetora. Apesar de suas fortes semelhanças com aquela exercida pelos missionários, tal tutela era pensada agora como uma atividade laica e influenciada pelo positivismo comtiano (portanto, com uma rigorosa exclusão das práticas religiosas).

\footnotetext{
${ }^{6}$ Por sertanismo me refiro ao conjunto de técnicas e saberes que, desde o século XVII, tem orientado as expedições de entrada pelo interior do Brasil (chamados "sertões", desabitados pelo homem branco). Aqueles que as dirigem são chamados "sertanistas" ou "bandeirantes".

7 Por rondonismo me refiro à doutrina relativa à proteção do índio desenvolvida pelo marechal Cândido Mariano da Silva Rondon, engenheiro militar de formação positivista, e suas equipes de colaboradores. Foi o fundador da agência indigenista oficial (SPI), dirigindo-a durante várias décadas. Seu ideário associa as técnicas do sertanismo à disciplina militar, apoiando-se em pensadores nacionais (principalmente do romantismo) e no evolucionismo de Auguste Comte.
} 
Entretanto, nas décadas de 1940 e 1950, este panorama foi alterado. Através de mútuas visitas e de intercâmbios mais frequentes, as experiências que tiveram lugar no México e nos Estados Unidos conduziram a uma redefinição das formas de intervenção da agência oficial (SPI), cuja atuação a partir dali se apoiou em uma colaboração estabelecida entre administradores e antropólogos. A própria agência indigenista e seu fundador, o marechal Rondon, foram classificados a posteriori por Darcy Ribeiro (1970) como "indigenistas" 8 , passando supostamente a seguir bem de perto o modelo mexicano.

A participação de antropólogos no SPI se tornou um fato estratégico e nada estranho. Na década de 50, três dos principais etnólogos brasileiros desenvolveram ali seus estudos e investigações: Darcy Ribeiro, Eduardo Galvão e Roberto Cardoso de Oliveira. ${ }^{9}$ Em 1955, em reunião da recém-fundada Associação Brasileira de Antropologia (ABA), Galvão falava sobre a necessidade de um ambicioso programa de pesquisas no qual os antropólogos desenvolveriam estudos que ajudariam a prover modelos de atuação do Estado a respeito de suas populações indígenas tradicionais. Ao concluir, enunciou um lema que seria muitas vezes repetido na antropologia brasileira, reafirmando a dupla lealdade do antropólogo aos elevados princípios da ciência à qual pertence e ao compromisso com o destino das populações estudadas.

Tal preocupação repercutirá igualmente na formação de um novo objeto de investigação para a antropologia brasileira, com os estudos de fricção interétnica desenvolvidos por Roberto Cardoso do Oliveira ${ }^{10}$ e seus discípulos, inspirados nas formulações de Georges Balandier ("situação colonial"), e Rodolfo Stavenhagen e Pablo Casanova ("colonialismo interno").

A instauração de um governo militar em 1964 evidentemente anulou a possibilidade de qualquer diálogo entre os antropólogos brasileiros e a administração pública, tornando inviáveis, inclusive, aquelas investigações que estivessem explicitamente em sintonia com os ideais de amparo às sociedades e às culturas indígenas. Enquanto isso, os antropólogos egressos dos cursos de pós-graduação implantados no país em 1968 (no Museu Nacional do Rio de Janeiro e na Universidade de São Paulo) deram continuidade a esta vertente de análise em antropologia, elaborando dezenas de etnografias sobre os povos indígenas e realizando importantes aperfeiçoamentos teóricos e metodológicos.

É importante notar que no caso dos estudos sobre a população negra e as tradições religiosas afro-brasileiras os processos cognitivos tiveram uma marca muito diferente.

\footnotetext{
${ }^{8}$ Veja-se especialmente a segunda parte do livro, dedicada a Rondon.

${ }^{9}$ Para uma descrição da inter-relação de antropólogos e indigenistas nesse período, ver Antonio Carlos de Souza Lima (2008).

${ }^{10}$ Entre outros igualmente importantes, ver os livros de Roberto Cardoso de Oliveira publicados em 1964 e 1978.
} 
Primeiro porque, até muito recentemente (anos 90), não existia nenhuma política oficial de amparo a tais coletividades. Ao contrário, nas últimas décadas do século XIX e até a metade do XX, os "terreiros de candomblé"11 foram objeto frequente de perseguições policiais, com a apropriação de seus objetos rituais e a prisão de seus oficiantes.

Em segundo lugar, desde os anos 40 havia surgido uma nascente mobilização urbana de intelectuais negros, que não só reivindicavam o espaço de uma representação política, mas também promoviam estudos e investigações de maneira independente e através de intelectuais orgânicos. Diferentemente dos indígenas - que eram objeto de uma política de tutela dos militares e de uma agência estatal específica - os negros tiveram que organizar-se para falar por si mesmos e reivindicar direitos. Assim até mesmo os estudos desenvolvidas por antropólogos e folcloristas sobre as religiões afro-brasileiras sempre estiveram justificados por fortes relações de empatia, vínculos rituais e filiação religiosa com as comunidades e costumes investigados (ainda que tais relações sejam pouco faladas e raramente refletidas enquanto forma de abordagem e construção de conhecimentos).

É importante recordar também que no período pós-Segunda Guerra Mundial, com o estabelecimento de programas de ajuda internacional e a ideologia da modernização como impulso para o desenvolvimento do terceiro mundo, os estudos antropológicos produziram um novo "outro", as populações rurais, focalizando as práticas e os costumes que indicavam uma continuidade de modos de vida tradicionais. Os antropólogos, ao contrário das expectativas das agências governamentais, evidenciaram a organização social e a racionalidade subjacente a tais coletividades - frequentemente tratadas como "atrasadas" e "irracionais". Os "outros internos" passaram a ser igualmente os camponeses e, por extensão aos seus segmentos deslocados para las cidades, também os "favelados"12. Por sua vez, os estudos críticos sobre a população negra no Brasil evidenciaram que ela não devia ser abordada apenas em termos estritamente culturais, mas sim como fenômeno de classe e estratificação social ${ }^{13}$.

A agência oficial indigenista se manteve rigorosamente à margem de qualquer colaboração com os antropólogos até a década de 90, sob o comando de administrações militares que obstaculizavam a realização de investigações acadêmicas e intervinham diretamente para evitar ações autônomas de defesa de seus direitos. Apenas durante um breve período (entre 1975 e 1978), foram delineados e iniciados, com o concurso de

\footnotetext{
${ }^{11}$ Locais onde são realizadas as cerimônias religiosas de origem africana. O termo "terreiro" indica um lugar aberto e de ocupação temporária, remetendo-se a um período em que tais ritos e cultos eram clandestinos e qualificados como práticas ilegais.

${ }^{12}$ Chamam-se favelados as pessoas que vivem em favelas; estas são áreas habitacionais em núcleos urbanos de população pobre (ocupando as zonas altas e as periferias das cidades), originadas em grande parte por famílias que abandonaram a região rural.
}

${ }^{13}$ Vide Ianni, 1966 e Fernandes, 1972 e 1978. 
antropólogos, alguns programas dirigidos a povos específicos (Yanomami, Ticuna, Rio Negro, Nambiquara, Guarani e Gavião). A partir dai os antropólogos formados pelos cursos de pósgraduação existentes só puderam intervir no destino das populações indígenas unicamente através de entidades civis criadas em algumas capitais a partir de $1978^{14}$ e que mantinham ações coligadas com líderes indígenas e missionários católicos "progressistas" (reunidos no Conselho Indigenista Missionário - CIMI e na OPAN).

No Brasil a trajetória acadêmica é iniciada com uma graduação genérica em Ciências Sociais, comportando áreas de concentração em sociologia, antropologia e ciências políticas ${ }^{15}$. Uma formação específica em antropologia só tem lugar na pós-graduação (mestrado e doutorado). Isto é reconhecido até pela própria associação profissional (ABA), que só admite como sócios plenos os portadores de, no mínimo, um diploma de mestrado em antropologia. Só recentemente, com a grande expansão das pós-graduações (que, em 40 anos, passaram de apenas dois núcleos estabelecidos no eixo Rio de Janeiro/São Paulo a 17 programas distribuídos por todas as regiões do país), está se iniciando um debate sobre a criação de uma carreira acadêmica específica em antropologia.

Nas décadas de 1980 e 1990, com o fim dos governos militares (1964-1984), o retorno à democracia e uma nova Carta constitucional (1988), surgiram novas demandas da sociedade em relação aos antropólogos. Estes, estimulados por linhas de investigação que recém se consolidavam nas antropologias hegemônicas (como os estudos de gênero, etnicidade, poder e sexualidade), criaram uma pauta de trabalhos extremamente diversificada na antropologia brasileira. Sob os rótulos genéricos de "minorias", "direitos coletivos" e "novas identidades", implicando numa reconfiguração da disciplina no país e instituindo novos objetos de conhecimento ${ }^{16}$. Por sua vez tais antropólogos mantiveram uma permanente interlocução com movimentos sociais, organismos públicos, entidades não governamentais e agências internacionais.

Deve se dedicar especial atenção aos chamados "laudos" ou "perícias" antropológicas, estudos encomendados a antropólogos por autoridades administrativas ou judiciais preocupadas em instruir processos e fundamentar suas decisões. Na esfera

\footnotetext{
${ }^{14}$ Foi o caso das Comissões Pró-Índio do Rio de Janeiro, São Paulo e Acre e da Associação Nacional
} de Apoio aos Índios/ANAI, de Porto Alegre, ljuí, Salvador e Brasília.

${ }^{15}$ Até poucos anos atrás a única exceção era a Universidade de Brasília. Atualmente porém novos campi universitários estão instituindo graduações em Antropologia (Rio Tinto/PB, Tabatinga/AM e Pelotas/RS).

16 Um exemplo desta nova forma de conceber e articular objetos distintos de conhecimento, enraizados todos em um contexto histórico preciso e referidos a uma problemática teórica, é a criação de nosso laboratório de investigação no Museu Nacional (Laced/Laboratório de Estudos sobre Etnicidade, Cultura e Desenvolvimento), cuja linha de investigação inclui os povos indígenas, os afrodescendentes, as questões de gênero e minorias, as políticas públicas, os movimentos sociais e as periferias urbanas. 
administrativa, trata-se de estudos e trabalhos de campo realizados por antropólogos em função de uma solicitação formal da agência indigenista, tendo como objetivo a delimitação de terras para as coletividades indígenas. Na esfera jurídica, os antropólogos atuaram como peritos em assuntos indígenas, esclarecendo questões de teor antropológico. Como o reconhecimento dos direitos indígenas deve estar apoiado em considerações de ordem antropológica, são justamente os indígenas os primeiros interessados em mobilizar seus etnógrafos para a execução de tais trabalhos.

Em algum momento de suas carreiras, perto de dois terços dos etnólogos brasileiros tiveram que dedicar inteiramente toda a sua energia e competência profissional à realização de tais laudos e perícias, que atualmente chegam a cerca de três centenas. Embora tais saberes tenham sido geralmente classificados pelos programas de pós-graduação como atividades de extensão ou trabalhos aplicados, foram fundamentais para a formação da maioria dos antropólogos brasileiros; além disso, ali aparecem dados e interpretações originais e de grande relevância para o conhecimento dos povos indígenas em sua contemporaneidade ${ }^{17}$.

Mas como são entendidas tais mudanças na antropologia, seja nos estudos sobre indígenas, seja nas novas áreas da disciplina? Uma perspectiva simplista, apoiada em uma visão positivista e evolucionista da história desta ciência, pretende que se trata tão somente da extensão da investigação antropológica a novos objetos. O que de fato acontece é algo bem diferente. Os trabalhos antropológicos que resultam destas novas linhas de investigação representam respostas a situações etnográficas múltiplas e bastante distintas do típico cenário colonial, implicando em uma reelaboração de métodos e objetivos da própria disciplina. Na realidade impõem uma transformação qualitativa da herança clássica e mantem também um diálogo intenso com perspectivas críticas surgidas nas antropologias hegemônicas.

As verdades operacionais que geraram as condições de possibilidade da prática antropológica, que formaram seus gostos e valores e que no passado permitiram a cristalização de uma identidade própria para o antropólogo, vão sendo modificadas e substituídas a partir de experiências novas, as quais precisam ser verbalizadas através de parâmetros científicos não convencionais. Ocupar-se de forma rigorosa e consciente em analisar e tornar claras estas novas condições do trabalho antropológico, refletindo cuidadosamente sobre elas, é o melhor meio para fazer avançar o conhecimento. Trabalhar de forma científica não é reproduzindo acriticamente padrões científicos consagrados no

\footnotetext{
${ }^{17}$ Para uma análise dos laudos e seu impacto na renovação teórica da antropologia brasileira, veja-se Pacheco de Oliveira (2008), bem como uma recente compilação (PACHECO DE OLIVEIRA; MURA; BARBOSA, 2015).
} 
passado, mas sim ser capaz de recuperar a singularidade e a originalidade da experiência de conhecimento que está sendo agora vivenciada.

É necessário apreender o conhecimento antropológico como produção social e histórica e enquanto processo prático. Ele não resulta de uma convergência universal e absoluta, mas muitas vezes se apoia em tradições que não se apresentam como necessariamente convergentes nem complementares. São tais tradições etnográficas que precisam ser identificadas e analisadas, permitindo assim escapar da perspectiva puramente normativa do positivismo continuísta.

As autorrepresentações da disciplina caminham com muito mais lentidão do que as transformações registradas no interior da prática concreta da investigação antropológica. É uma atitude nostálgica chamar "clássicas" à reificação de formulações dos pais-fundadores da antropologia (os quais respondiam a exigências políticas e cognitivas de construção de uma modalidade específica de saber, inserida dentro de um marco colonial preciso, hoje inteiramente modificado). O caminho para as antropologias periféricas não é importar pura e simplesmente os dilemas e os desafios presentes na agenda da antropologia metropolitana. Tais autores e interpretações precisam ser enquadrados em seu contexto histórico, em vez de serem petrificados em recomendações normativas genéricas e a-temporais, repetidas nos manuais e nos ritos acadêmicos de ingresso e consagração na carreira de antropologia.

\section{À MANEIRA DE CONCLUSÃO: OS DESAFIOS ATUAIS}

Assim como é necessário revelar o quadro colonial como fundamento das verdades operacionais presentes nas autorrepresentações mais convencionais do trabalho do antropólogo, é igualmente importante prestar atenção em como o cenário político se alterou radicalmente nas últimas décadas. Hoje, as jovens nações e os antigos impérios coloniais não estão totalmente livres para seguir tradições jurídicas ou administrativas próprias em relação aos povos indígenas. Existem importantes regulações internacionais que intervêm através de sanções em diversas instâncias, assim como também por intermédio da condenação moral e pública. Agências internacionais e multilaterais também estabeleceram critérios que devem orientar as relações dos Estados-nação com suas populações autóctones.

No mundo globalizado de hoje em dia, as diferenças culturais internas às unidades nacionais deixaram de ser objeto de censura ou dissimulação. Pelo contrário, as diferenças culturais são exploradas pela indústria do turismo e do tempo livre, domesticadas através de políticas públicas (multiculturalismo). Podem também algumas vezes ser usadas como fermento gerador de novas formas de mobilização e utopias sociopolíticas, especialmente em face da diminuição da atração exercida pelas ideologias universalistas. Por outro lado, as 
populações autóctones já não se fazem representar exclusivamente por líderes locais ou tradicionais articulados com estruturas coloniais, mas sim dispõem cada vez mais de seus próprios intelectuais (professores bilíngues, estudantes universitários, técnicos, pastores etc.), articulando-se progressivamente em associações integradas em redes, que vão desde a aldeia até uma representação continental ou mundial.

O que o jovem antropólogo investigará no campo já não pode mais ser o fruto exclusivo de um interesse acadêmico, puramente justificado por sua relevância científica e decidido entre ele, seu orientador de tese e a instituição universitária ou equipe de investigação à qual está vinculado. É necessário que os líderes da comunidade investigada compreendam as finalidades e o modus faciendi da investigação, aprovando-a ou exigindo reformulações. Invadir a intimidade de grupos e famílias, revelar fórmulas privativas de certos segmentos, coletar indiscriminadamente artefatos ou espécies naturais são práticas daninhas que não devem ser atualizadas. Qualquer forma de registro deverá ser objeto de uma negociação direta com os indígenas bem como com todos os demais "outros" dos antropólogos, precedida de uma "consulta informada" que lhes apresente minuciosamente as implicações que podem estar em jogo.

Atualmente, já não se trata de um compromisso ou responsabilidade pessoal ("personal accountability") exigida ao antropólogo por seus pares, como acontecia há quase quatro décadas atrás (JORGENSEN; WOLF, 1970; CONDOMINAS, 1973; BARTH, 1974). Hoje em dia, o que mais importa aos indígenas é o tema do controle sobre os múltiplos usos que podem chegar a ter os dados resultantes da investigação etnográfica. É fundamental saber em que medida as análises e as interpretações elaboradas podem afetar seu modo de vida, seus direitos e as representações sobre eles mesmos.

Como uma premissa essencial a esta nova relação, o investigador é convidado a abandonar qualquer simulação de neutralidade, envolvendo-se extensamente com as demandas mais urgentes dessas coletividades. Se anteriormente isto foi firmado através de um documento político (Declaração de Barbados, 1971), hoje se fundamenta em novos pressupostos analíticos ${ }^{18}$ e importantes consensos estabelecidos entre diferentes "saberes regionalizados" (africanistas, orientalistas, oceanistas e americanistas).

Nas últimas décadas do século passado aconteceram mudanças importantes no contexto brasileiro, com um processo de redemocratização e fortes investimentos em programas de inclusão social por parte de mecanismos de cooperação internacional. O sistema de "chefias" supostamente tradicionais, articuladas com o poder das agências oficiais e dentro do horizonte político das "administrações indiretas", começou a demonstrar sua fragilidade, ficando evidente que se tornava cada vez mais difícil e questionada a unidade de

\footnotetext{
${ }^{18}$ Como a teoria do discurso, a crítica hermenêutica e a antropologia do colonialismo.
} 
ação e pensamento de qualquer das antes chamadas "etnias". De agora em diante, os antropólogos têm que estudar povos e culturas cuja existência se manifesta de forma mais fragmentada e diversificada, e que coexistem com o dinamismo das disputas por representatividade em múltiplos níveis (gerações, facções, religiões etc.).

Em relação à perspectiva dos indígenas, nota-se uma modificação progressiva. Uma vez superada a etapa de afirmação e reconhecimento básico dos direitos indígenas, a condição de "especialista" que um antropólogo pode chegar - equivocadamente - a assumir no que concerne a uma determinada cultura, incomoda cada vez mais àqueles que acionam essas identidades em suas disputas cotidianas. O fato de que uma pessoa de fora, que pode escapar aos mecanismos locais de controle, venha a ser colocada em uma posição de autoridade (logrando de algum modo arbitrar sobre questões que são objeto de discussão e reformulação coletiva), pode constituir-se em uma ameaça para os novos intelectuais e líderes indígenas. Aqui se registra uma crescente reivindicação para que os investigadores e os etnógrafos sejam os próprios indígenas, o que desnivelaria menos as disputas por consenso, por interpretações autorizadas ou por autenticidade.

A possibilidade de que os indígenas comecem a disputar um espaço de representação, onde anteriormente o antropólogo transitava com relativa liberdade e com inquestionável legitimidade científica, certamente trará muitas consequências importantes para as novas formas do "fazer antropológico". O antropólogo precisará explicar melhor a especificidade de seu olhar e de seu conhecimento, tanto diante das coletividades que estuda como diante das diferentes esferas governamentais e da opinião pública.

Considerando também a enorme ampliação de seu campo de investigação, o surgimento de novos temas e métodos, assim como a existência de elos importantes com outras disciplinas, impõe-se uma reflexão que possa fundamentar novas posturas científicas. Sobretudo é preciso repensar as autorrepresentações estáticas e confortáveis da disciplina, pois o que está em debate é a própria natureza do conhecimento antropológico.

Рага encerrar, eu gostaria de reiterar o meu desconforto com a autorrepresentação habitual da Antropologia, seja em contextos periféricos, ou metropolitanos, associada a uma visão normativa e homogeneizadora da ciência e limitada por uma perspectiva eurocêntrica ${ }^{19}$. Os projetos de formação institucional nas antropologias periféricas precisam ser analisados não por meio das autorrepresentações engendradas a partir da importação descontextualizada de conhecimentos, mas sim através de uma análise cuidadosa das práticas concretas de investigação atualizadas, observando os resultados produzidos e procurando tomar consciência do campo de possibilidades que instauraram e também de seus limites.

\footnotetext{
${ }^{19}$ Ver Ribeiro e Escobar (2006), Restrepo e Escobar (2005), cujas elaborações apontam firmemente nesta direção.
} 
Longe de ser uma construção arquitetônica uniforme e integrada, a antropologia pode abrigar domínios bastante diferenciados, com saberes regionalizados (FARDON, 1990) e tradições etnográficas específicas, poir meio dos quais se processa efetivamente a transmissão concreta e a modificação de práticas de investigação, algumas vezes com fortes aproximações com autores e procedimentos de outras disciplinas.

Pensar as tradições etnográficas de maneira plural, como resultado de uma autoconsciência progressiva quanto à eficácia e à singularidade de práticas setoriais de investigação, pode representar uma forma positiva e criativa para escapar à pressão repressora e homogeneizadora de uma normatividade referida a momentos passados da história da disciplina. As verdades operacionais não devem tão somente estar ligadas a uma tradição etnográfica "colonial" ou metropolitana, mas sim precisam refletir as condições de possibilidade das investigações em execução no mundo contemporâneo.

\section{REFERÊNCIAS BIBLIOGRÁFICAS}

BARTH, Fredrik. On responsibility and humanity: calling a colleague to account. Current Anthropology, v. 15, n. 1, p. 99-102. Wenner-Gren Foundation for Anthropological Research, 1974.

Balinese Worlds. Chicago: The University of Chicago Press, 1993.

BAZIN, Jean. Science des moeurs et description de l'action. Actualités du contemporain. Le genre humain, n. 35, p. 13-43. Paris: Seuil, 2002.

BENSA, Alban. La Fin de l' Exotisme. Marseille: Anarchasis, 2006.

BOURDIEU, Pierre. Ce que parler veut dire: l'économie des échanges linguistiques. Paris: Fayard, 1997.

CARDOSO DE OLIVEIRA, Roberto. O índio e o mundo dos brancos. São Paulo: Difel, 1964.

.A Sociologia do Brasil Indígena. Rio de Janeiro: Tempo Brasileiro, 1978.

Peripheral antropologies "versus" central anthropologies. The Journal of Latin American and Caribbean Anthropology, 4 (2), p. 10-31, 1999.

CHASE SMITH, Richard (comp.). Pueblos Indígenas de América Latina: Retos para el nuevo Milenio. Lima: Fundación Ford/Oxfam América, 2002. CD-ROM.

CONDOMINAS, G. Notes sur la situation actuelle de l'anthropologie dans le tiers monde. Comunicação apresentada na Association of Social Anthropologists, Decennial Conference, celebrada em junho em Oxford, 1973.

COPANS, Jean ; JAMIN, Jean. Aux origins de l'anthropologie française: les mémoires de la socièté des Observateurs de l'Homme en l'an VIII. Paris: Le Sycomore, 1978. 
EVANS-PRITCHARD, E.E.; FORTES, M. Introduction. In: (eds.). African Political Systems. London: African International Institute/Oxford University Press, 1970 [1940].

FARDON, R. Localizing strategies: regional traditions of ethnographic writing. Edimburgh e Washington: Scottish Academic Press/Smithsonian Institution, 1990.

FERNANDES, FLORESTAN - 0 negro no mundo dos brancos. São Paulo, Difusão Européisa do Livro, 1972.

.A integração do negro na sociedade de classes. São Paulo, Atica, 1978.

GRUNBERG, Georg (org.). Articulación de la diversidad: Tercera reunión de Barbados. Quito: Abya Yala, 1995.

IANNI, OCTAVIO - Raças e classes sociais no Brasil. Rio de Janeiro, Civilização Brasileira, 1966.

JORGENSEN, Joseph G.; WOLF, Eric. Anthropology on the Warpath in Thailand. The New York Review of Books, v. 15, n. 9, p. 26-35, 19/11/1970. Disponível em: http://www.nybooks.com/articles/10763. Acesso em: 20/02/2010.

KUPER, Adam. Anthropology and anthropologists: The British School 1922-1972. London: Allan Lane, 1973.

.Culture: the anthropologist's account. Cambridge: Harvard University Press, 1999.

KROTZ, Esteban. La otredad cultural entre utopia y ciencia: Un estudio sobre el origen, el desarrollo y la reorientación de la Antropología. Madrid: Fondo de Cultura Económica de España, 2002.

L'ÉTOILE, Benoit. L'Afrique comme laboratoire: expériences réformatrices et révolution anthropologique dans l'empire colonial britanique (1920-1950). Tese (Doutorado em Anthropologia Social) - Paris, École des Hautes Études en Sciences Sociales, 2004.

LIMA, Antonio Carlos de Souza. Indigenism in Brazil: migration and reapropriation of an administrative knowledge. In: L'ESTOILE, B.; NEIBURG, F.; SIGAUD, L. (eds.). Empires, Nations, and Natives. Anthropology and State-making. Duham: Duke University Press, 2008.

MICELI, Sergio. A Fundação Ford no Brasil. São Paulo: Sumaré, 1993.

PACHECO DE OLIVEIRA, João. Pluralizando tradiciones etnográficas: Sobre un cierto mal estar en la Antropologia. In: _. . Hacia una Antropología del Indigenismo. Lima e Rio de Janeiro: CAAAP/Contra Capa, 2006. p. 201-218.

.The anthropologist as expert: Brazilian Ethnology between indianism and indigenism. In: L'ESTOILE, B.; NEIBURG, F.; SIGAUD, L. (eds.). Empires, Nations, and Natives. Anthropology and State-making. Duham: Duke University Press, 2008. p. 223-247.

Contemporary indigenous politics in Brazil: Three modes of indigenous political performance. In: SINGH, Priti (ed.). Indigenous Identity and Activism. Delhi: Shipra, 2009. p. 80-103. 
.As mortes do indígena no Império do Brasil: 0 indianismo, a formação de nacionalidade e seus esquecimentos. In: AZEVEDO, Cecília et al. (orgs.). Cultura política, memória e historiografia. Rio de Janeiro: Fundação Getúlio Vargas, 2009.

.Etnografia enquanto compartilhamento e comunicação. Desafios atuais às representações coloniais da Antropologia. In: FELDMANN-BIANCO, Bela (ed.). Desafios da Antropologia Brasileira. ABA Publicações, 2013.

PACHECO DE OLIVEIRA, J.; MURA, F.; BARBOSA, A. (eds.). Laudos Antropológicos em Perspectiva. ABA Publicações, 2015.

PELS, Peter; SALEMINK, Oscar. Colonial subjects: essays on the practical history of anthropology. Ann Arbor: University of Michigan Press, 1999.

RESTREPO, Eduardo; ESCOBAR, Arturo. "Other anthropologies" and "anthropology otherwise": steps to a world anthropology network. Critique of Anthropology, 25 (2), p. 99-128, 2005.

RIBEIRO, Darcy. Os índios e a civilização. 2. ed. Rio de Janeiro: Civilização Brasileira, 1970.

RIBEIR0, Gustavo Lins; ESCOBAR, Arturo. World Anthropologies: Disciplinary Transformations in Systems of Power. In: __ (eds.). World Anthropologies: Disciplinary Transformations in Systems of Power. Oxford: Berg, 2006. p. 1-25.

STOCKING, George W. Race, culture, and evolution: essays in the history of Anthropology. Chicago The University of Chicago Press, 1968.

Press, 1974.

Shaping of American Anthropology, 1883-1911. Chicago: The University of Chicago

.Functionalism historicized: Essays on British social anthropology. Madison: The University of Wisconsin Press, 1984.

.Observers observed: essays on ethnographic field work. Madison: The University of Wisconsin Press, 1984.

.Colonial situations: essays on the production of anthropological knowledge. Madison: The University of Wisconsin Press, 1988.

.Volkgeist as method and ethic: essays on boasian ethnography and the German anthropological tradition. Madison: The University of Wisconsin Press, 1996.

.Unfinished business: Robert Gelstom Armstrong, the Federal Bureau of Investigation, and the history of Anthropology in Chicago and at Nigeria. In: HANDLER, Richard (ed.). Central sites, peripheral visions: cultural and institutional crossings in the history of anthropology. Madison: University of Wisconsin Press, 2006. p. 99-247. 